\title{
Die Aufzeichnungen des Malte Laurids Brigge: novas perspectivas de interpretação
}

\author{
Die Aufzeichnungen des Malte Laurids Brigse: new interpretation perspectives
}

\section{Renata Martins}

\begin{abstract}
The objective of this text is to analyze the stranger's experience in the novel Die Aufzeichnungen des Malte Laurids Brigge by Rainer Maria Rilke through new interpretation perspectives based, for example, on Sigmund Freud's psychoanalytic theories. Living in a foreign metropolis (Paris), which he does not identify with yet, the novel's protagonist, Malte Laurids Brigge, discovers a new inner world through his shock with stranger's experiences in this environment. The revelation of his childhood memories and his ego projection through readings of narratives by others are his methods to search and assert his identity.
\end{abstract}

Key-words: identity, alien experience, metropolis, inner world

Resumo: O objetivo deste texto é analisar a experiência do estranho no romance Die Aufzeichnungen des Malte Laurids Brigge, de Rainer Maria Rilke, através de novas perspectivas de interpretação apoiadas, por exemplo, nas teorias psicanalíticas de Sigmund Freud. Vivendo em uma cidade estrangeira (Paris), com a qual ainda não se identifica, o protagonista do romance, Malte Laurids Brigge, descobre um mundo interior novo através de seu choque com experiências do estranho nesse milieu. A revelação de recordações de sua infância e a projeção de seu ego em leituras de narrativas alheias são seus métodos para buscar e afirmar sua identidade.

Palavras-chave: identidade; experiência do estranho; metrópole, mundo interior

\footnotetext{
* Mestre em Literatura Alemã pela Universidade de São Paulo. Email: renata.martins@gmx.de
} 
Martins, R. - Malte Laurids Brigge: novas perspectivas

\section{Introdução}

O romance Die Aufzeichnungen des Malte Laurids Brigge ${ }^{1}$, publicado em 1910, é considerado o opus magnum ${ }^{2}$ da prosa de Rainer Maria Rilke (1875-1926). Dedicando seis anos à obra, ainda que não consecutivos, o autor procurou ao longo desse período imprimir em seu fazer artístico um contínuo e minucioso ritmo de trabalho - legado incontestável de seu contato com os modelos de produção do pintor Paul Cézanne e do escultor Auguste Rodin. Mediante o contato com as artes plásticas e a escultura, Rilke adota para si o programa do toujours travallier, sempre trabalhar, como observa Franz LOQUAI (in RILKE 2005: 214)3. A rigorosa dedicação à produção do romance é observada por críticos como uma forma meticulosa, incessante e altamente exigente do autor de buscar novas e adequadas formas de expressão a sua prosa, como observa Franz Loquai (in RILKE 2005: 213) ${ }^{4}$. Em uma carta à amiga Lou Andreas-Salomé, o próprio autor admitiu seu novo modo de trabalhar e sua necessidade de ter um longo tempo para dedicar-se à escrita, fatores que considerava um progresso resultante de seu aprendizado do toujours travallier ${ }^{5}$. Contudo, Die Aufzeichnungen des Malte Laurids Brigge não apenas se tornou um marco na vida e na produção artística de Rilke, mas também se estabeleceu decisivamente na história da literatura alemã do século XX, pois é apontado pela crítica literária como o primeiro romance moderno em língua alemã (Cf. Leiss, StAdler 2004: 162; Petersen 1991: 68) e um dos mais importantes textos

\footnotetext{
${ }^{1}$ O romance foi traduzido ao português por Lya Luft sob o título Os cadernos de Malte Laurids Brigge (1996).

${ }^{2}$ O crítico Franz Loquai afirma: "Als Rainer Maria Rilke den Malte Laurids Brigge zu schreiben begonnen hatte, war ihm bewusst, daß es sich um sein opus magnum in Prosa handeln würde." (in: RILKE 2005: 213). [Quando Rainer Maria Rilke começou a escrever Malte Laurids Brigge, estava consciente de que se tratava de sua opus magnum em prosa.] Já o crítico August Stahl observa: "Rilke hat von Anfang an und zeit seines Lebens den Malte für eines seiner bedeutenden Werke gehalten, für ein 'opus magnum'.”, (in: RILKE 1996: 878). [Rilke considerou Malte desde o princípio e ao longo de sua vida como um de seus significativos trabalhos, como um grande trabalho - opus magnum].

${ }^{3}$ Hans Egon Holthusen cita uma carta de Rilke à mulher, Clara Rilke, observando o modo de trabalho de Rodin: "Er (Rodin) schwieg eine Weile und sagte dann, wunderbar ernst sagte er das: il faut travailler, rien que travailler, Et il faut avoir patience." (HOLTHUSEN 1990: 74). [Ele se calava um momento e dizia então, maravilhosamente sério dizia isso: il faut travailler, rien que travailler, Et il faut avoir patience.]

${ }^{4}$ "Schon dieser Arbeitsrhythmus läßt darauf schließen, daß es sich Rilke nicht leicht gemacht hat, weil er, auf der Suche nach neuen, seinem Thema adäquaten Ausdrucksformen der Prosa, höchste Ansprüche an sich selbst stellte."

5“[...] da zeigte es sich, daß meine Arbeitsweise (ebenso wie mein viel aufnehmenderes Schauen) sich geändert hat, so daß ich wohl nie mehr dazu kommen werde, ein Buch in zehn Tagen (oder Abenden) zu schreiben, vielmehr für ein jedes lange und ungezählte Zeit brauchen werde; das ist gut, es ist ein Fortschritt nach dem Immerarbeiten hin [...]" (RILKE 1996: 867).
} 
Martins, R. - Malte Laurids Brigge: novas perspectivas

em prosa do século $\mathrm{XX}$ :

Dieser als 'Roman' apostrophierte, aus tagesbuchartigen Aufzeichnungen zusammengesetzte Text gehört, zusammen mit Döblins 'Berliner Alexanderplatz', zu den wichtigsten Prosatexten der deutschen Literatur des 20. Jahrhunderts, die sich am Thema Großstadt abarbeiten. (VIETTA 1992: 305) ${ }^{6}$

Vale observar que tais considerações sobre a importância do romance no campo dos estudos literários foi defendida pela crítica especializada décadas depois de sua publicação, como aponta Heide Eilert: "Doch Jahrzehnte dauert es, bis sich die Einsicht durchsetzte, dass ausgerechnet einer der bedeutendsten Lyriker seiner Zeit zugleich den ersten Roman der Moderne verfasst hatte." (2000:43) ${ }^{7}$. O reconhecimento tardio dessa obra deve-se à recepção negativa que recebeu, tendo sido classificada como um romance estranho, de tom polêmico e pretensioso, desde a escolha de seu título até o seu encerramento mal-acabado, e de difícil leitura - fator ocasionado por um pressuposto poético que direcionava o romance a um seleto e diminuto público (RILKE 1996: 888891). Outro motivo para a falta de receptividade inicial aponta a reação de repulsa dos críticos literários da época ao emprego de elementos e formas utilizados por Rilke, que propunha abertamente o rompimento com a tradicional prosa narrativa em língua alemã e com o realismo poético, amplamente divulgado e utilizado como modelo para romances desse momento (Cf. GRIMMINGER1995: 526). O autor, abdicando da herança e dos moldes literários então vigentes e abandonando as tradicionais expectativas de leitura (RILKE 2005: 233) - típicas nos romances da virada do século -, utilizou em Malte uma ousada proposta estética cuja forma preza pela fragmentação textual. Ademais, observa-se no romance a ausência de uma coerência narrativa capaz de proporcionar uma ligação entre suas setenta e uma anotações e de tecer um desenvolvimento linear do foco narrativo.

Ainda que propondo uma ruptura com a tradição literária e a herança das narrativas europeias, Rilke bebeu diretamente de diversas fontes nos campos de conhecimento da cultura ocidental e não ocultou a influência que elas tiveram na

\footnotetext{
6 "Este texto, designado como 'romance' e composto por anotações de diário, pertence, juntamente com Berliner Alexanderplatz, de Döblin, aos textos em prosa mais importantes da literatura alemã do século XX que se ocupa do tema da cidade grande."

7 "Durou décadas até que se instaurasse a noção de que um dos mais significativos líricos de seu tempo havia simultaneamente composto o primeiro romance da modernidade."
} 
Martins, R. - Malte Laurids Brigge: novas perspectivas

composição do romance. Como aponta August Stahl, é difícil defini-las categoricamente (in RILKE 1996: 882-888), porém é possível reconhecê-las quando são aludidas pelo protagonista-narrador, o jovem Malte Laurids Brigge. Além disso, encontram-se diluídas na ficção inúmeras vivências de formação (Bildungserlebnisse) do próprio autor, assim como seus conhecimentos sobre a história francesa e russa e sobre a arte, especialmente a pintura, e suas recordações infantis e de leituras passadas. Em relação à sua forma, tem-se no romance a composição de um amplo e multifacetado mosaico de anotações de Malte. Para isso, Rilke fez uso da apresentação de reflexões, descrições e recordações passadas do protagnista-narrador e da montagem de distintos gêneros textuais, que na maioria das vezes não têm um elo de concordância semântica entre si, mas se combinam nos momentos de necessidade comunicativa do narrador, como observa Jürgen PERTERSEN (1991:72). Há, por exemplo, a citação do poème en prose "Une charogne", de Charles Baudelaire, que remete a um largo parágrafo dedicado ao livro bíblico de Jó; encontram-se também o esboço de uma carta de Malte, um hino em prosa a Beethoven, a Ibsen e à atriz italiana Eleonora Duse, e um conto da mãe de Malte (Cf. PETERSEN 1991:72; RILKE 2005: 219). Verifica-se assim que Rilke logrou transportar ao seu romance o projeto estético idealizado pelos primeiros românticos do século XVII: o "romance-montagem”, ainda que em um nível moderado e de modo algum remontando conscientemente a esse legado, como aponta Jürgen PETERSEN (1991:68-72).

Devido à forma fragmentária e descontínua do texto, Rilke inovou ao renunciar a uma narrativa linear em Malte. Desmembrando pela primeira vez a ficção épica, o autor não estabelece nenhum sentido ou coerência a cada novo fragmento em relação ao anterior, como aponta Ingo LEIß: "Rilke ist der erste, der die epische Fiktion zertrümmert. Sein ,Malte Laurids Brigge' läßt keine Romanwelt als geschlossene Wirkung mehr zu. Der Autor stiftet nicht mehr Sinn und Zusammenhang.” (2004: 71). A única instância capaz de imprimir sentido aos diversos fragmentos e de interpretá-los é o leitor, o qual não tem uma tarefa muito fácil diante de si, já que ler Malte significa lê-lo muitas vezes e sempre, segundo Franz LOQUAI (in RILKE 2005: 220). Assim, o leitor goza de plena liberdade na recepção e na construção de sentido entre os fragmentos que tem diante de si. Essa forma consciente de construção aberta do romance pode ser considerada um radical ato estético de Rilke. E, através desse planejado caos narrativo, tem-se o reflexo da situação anímica do protagonista-narrador, 


\section{Martins, R. - Malte Laurids Brigge: novas perspectivas}

ou seja, o caos formal do romance reproduz visualmente e metaforicamente para o leitor o caos interior de Malte, que é incapaz de transmitir com suas próprias palavras seu mundo interior, em estado caótico.

A desestruturação formal e semântica da narrativa trabalhada por Rilke evidencia seu objetivo de colocar à prova a linearidade, o estabelecimento de uma ordem lógica e progressiva e a construção de uma realidade estável. Isso nos remete ao posicionamento radical que o romance adquiriu, a partir do século XIX, tanto em sua forma quanto em sua autoridade em relação à realidade ficcional, capaz de demonstrar o mal-estar do indivíduo na modernidade. Georg LUKÁCS observou, em 1915, no ensaio $A$ teoria do romance, que "a forma do romance, como nenhuma outra, é a expressão do desabrigo transcendental.” (2007: 37-38). A forma interna do romance seria, então, concebida seguindo "a peregrinação do indivíduo problemático rumo a si mesmo, o caminho desde o opaco cativeiro na realidade simplesmente existente, em si heterogênea e vazia de sentido para o indivíduo, rumo ao claro autoconhecimento." (2007: 82), já que para o crítico húngaro "ser homem" no mundo moderno "significa ser solitário" (2007: 34). Com base nesses argumentos, pode-se afirmar que Die Aufzeichnungen des Malte Laurids Brigge é um romance moderno não somente pela presença de diferentes gêneros textuais em sua forma, ou pelo rompimento com a linearidade da narrativa até então vigente, mas também porque expõe, em seu protagonista, o jovem estrangeiro Malte Laurids Brigge, as feridas do homem moderno: um indivíduo solitário, perdido em meio a uma multidão e em si mesmo. Ele é um taciturno estrangeiro à procura de sua identidade em um lugar de onde não provém e com o qual tampouco se identifica. Desorientado de e em si mesmo, torna-se um peregrino não apenas no mundo, mas também em relação a si próprio. Seu desconsolo e falta de integração são experienciados tanto em relação ao seu mundo exterior quanto ao seu mundo interior. E, ao contrário das epopeias tradicionais, não possui o respaldo intermediador e acolhedor de nenhuma entidade divina, que poderia intervir a seu favor em algum momento de dificuldade ou desolação de sua alma.

Ainda sobre os aspectos referentes à forma do romance, o crítico Franz LOQUAI aponta que seus fragmentos podem ser agrupados em três blocos temáticos gerais (in RILKE 2005: 222): 1. Presente em Paris (fragmentos de 1 a 26); 2. Recordações da infância (fragmentos de 27 a 53) e 3. Leituras de Malte (fragmentos de 54 a 71). Nos três, encontram-se a busca e a afirmação de Malte por sua identidade que, através de 


\section{Martins, R. - Malte Laurids Brigge: novas perspectivas}

experiências em seu momento presente em Paris, em sua infância e com suas leituras, apoiam e fomentam sua solitária odisseia rumo a si mesmo. Nessa desafiante jornada interna, ele conta com a presença crucial de acontecimentos raros, de "experiências do estranho" (Fremderfahrungen), que o acompanham, e provocam, desde seus primeiros anos de vida e sua introdução consciente ao mundo dos adultos, ao período em que se encontra na capital francesa. Captando o ambiente mórbido, caótico e fétido dessa cidade no início do século XX, Malte Laurids Brigge tem, através de "experiências do estranho", o aprendizado de ver ("Ich lerne sehen", - como o personagem admite já em sua quarta anotação). Tal aprendizado revela-lhe não apenas detalhes e percepções próprias sobre esse milieu urbano, mas também a existência de um mundo interior novo, até então encoberto aos seus olhos e tão caótico e desolador quanto seu meio externo. Obstinado com a tarefa de compreender esse novo mundo interior e, consequentemente, definir sua identidade, o jovem inicia uma viagem introspectiva, a qual projeta em uma instância mais elevada a situação anímica de desolação e as crises do homem moderno nos primeiros tempos do século XX.

Ao percorrer o espaço urbano como um silencioso e sombrio estrangeiro, seu aprendizado de ver converte-se em uma faca de dois gumes, pois não somente faz com que Malte perceba singularmente seu mundo externo, trazendo-o para seu interior, mas também projete em sua percepção desse mundo exterior o estado de sua alma. $\mathrm{O}$ canal comunicativo entre esses dois mundos do protagonista-narrador é fomentado e estimulado pela "experiência do estranho" (Fremderfahrung) em Paris. Ou melhor, no atordoante espaço urbano, Malte revive a "experiência do estranho", fenômeno que já lhe era familiar há tempos. No decorrer das anotações, o leitor dá-se conta de que tais experiências insólitas e a busca por sua identidade sempre estiveram presentes na vida de Malte, desde sua infância. Elas fizeram e continuam fazendo parte de sua formação e visão de mundo. Assim, pode-se observar que no momento em que se encontra em Paris e torna-se consciente da existência de um mundo interior que desconhecia, o jovem retoma uma questão central, que o acompanhara desde pequeno: ele foi e continua sendo um estranho para si mesmo; e, para tanto, necessita empreender uma jornada interna pela definição de sua identidade. Essa tomada de consciência da existência de

\footnotetext{
8 “Estou aprendendo a ver. Não sei o que provoca isso, tudo penetra mais fundo em mim, e não pára no lugar em que costumava terminar antes. Tenho um interior que ignorava. Agora, tudo vai dar aí. E não sei o que aí acontece.”. (RILKE 1996:8 - tradução de Lya Luft).
} 


\section{Martins, R. - Malte Laurids Brigge: novas perspectivas}

um novo mundo interior somente é possibilitada por "experiências do estranho" geradas pelo contato do plano subjetivo de Malte com a paisagem urbana e humana de Paris. Esse encontro permite ao jovem ter a percepção de que é um desconhecido para si próprio.

Na primeira anotação sobre a realidade externa parisiense, Malte evidencia o aspecto da massificação da vida do indivíduo urbano e da desvalorização que a morte ali recebe - fator oposto à conotação que aprendera em seu meio familiar ${ }^{9}$. Ora, sendo a morte o outro estado natural da vida humana, pode-se afirmar que Malte ilustra nela (a morte) a mesma massificação e depreciação do particular que um indivíduo tem em vida. Com isso, o jovem dinamarquês ilustra a falta de particularidade do indivíduo moderno, tanto em sua vida quanto em sua morte. O medo de ser mais um anônimo nessa realidade massificada e a descoberta de seu novo mundo interior desencadeiam no protagonista uma reação imediata da redefinição de si mesmo. Para isso, ele retoma recordações de sua infância e de leituras passadas que o motivaram outrora a buscar e a afirmar sua identidade e que também contêm "experiências do estranho" (Fremderfahrungen) como um fator essencial em sua constituição.

Já que a presença da "experiência do estranho" (Fremderfahrung) é para Malte o ponto desencadeador tanto para sua tomada de consciência sobre a existência de um mundo interior novo quanto para a definição e afirmação de sua identidade, vale observar que o termo alemão fremd aponta uma ardilosa polissemia que oculta em si um complexo conteúdo de significados (Cf. WALDENFELS 1997: 20). Em conformidade com os dicionários Wahrig-Großwörterbuch e Duden Universalwörterbuch, encontram-se os seguintes significados para a palavra fremd: "alguém proveniente de outro país, outra cidade, outro povo ou de outra família"; “estrangeiro", “estranho”, “desconhecido"; "que pertence a outra pessoa"; "que não me é familiar ou confiável”; "raro"; "insólito"; "não confiável”. Devido à polissemia da palavra é possível também construir uma vasta gama de termos correlatos, como: Fremdbild ("imagem estranha"); Fremdsprache ("língua estrangeira"); Fremdwort ("palavra estrangeira”); Fremdling ("pessoa estranha

\footnotetext{
9"Hoje, morre-se em 559 leitos. Produção em série, naturalmente. E numa produção dessas não se executa tão bem a morte individual, mas também isso é coisa que pouco importa. O que interessa é a quantidade. Quem, hoje, dá valor a uma morte bem executada? [...] faz-se cada vez mais raro o desejo de ter uma morte particular. Mais um pouco, e será tão raro quanto ter uma vida particular. [...] Quando penso em nossa casa, onde não mora mais ninguém, acho que outrora deve ter sido diferente [...] A gente possuía a morte, e isso dava uma singular dignidade, um orgulho silencioso". (RILKE 1996: 11 - tradução de Lya Luft)
} 
Martins, R. - Malte Laurids Brigge: novas perspectivas

ou estrangeira"); Fremdgut ("bem pertencente a um estranho"); Fremdmittel ("recursos alheios"); Fremdenhass ("xenofobia"); Fremdenverkehr ("circulação de estrangeiros/turismo"); Entfremdung ("alienação"); Verfremdung ("estranhamento"); fremdgehen ("ter uma relação extra-conjugal"); fremdeln ("sentir-se acanhado frente a estranhos") $)^{10}$.

O termo Fremderfahrung ("experiência do estranho"), ponto de partida para Malte descobrir seu novo mundo interior e sua identidade, tornou-se uma referência para os estudos do filósofo alemão Edmund Husserl, que dedicou trinta anos de sua vida (1905-1935) à pesquisa desse conceito. Na obra V. Cartesianische Meditation Enthüllung der transzendentalen Seinssphäre als monadologische Intersubjektivität ("V. Meditação Cartesiana - Determinação do domínio transcendental como intersubjetividade monadológica"), publicada em 1929, Husserl denomina o das/der Fremde ("aquilo ou aquele que é estranho ao Eu") como der Andere ("o Outro"), caracterizando-o como o primeiro Não-Eu (das erste Nicht-Ich), que permite ao Eu ter consciência de suas propriedades e particularidades. Ao dissecar o Eu em duas instâncias (uma transcendental e outra psico-física), Husserl aponta que o EuTranscendental, no confronto visual com o "Outro" (der Andere), detém deste somente sua representação, uma espécie de reflexo de quem ou do quê ele originalmente é. Com isso, a percepção do Eu-Transcendental conduz à experiência do estranho por permitirlhe ter acesso ao "inacessível original" que o "Estranho" (das/der Fremde) ou o "Outro" (der Andere) representa: "É nessa acessibilidade indirecta, mas verdadeira, daquilo que é inacessível directamente e em si mesmo que se funda para nós a existência do outro.”, (HUSSERL 2001: 146) ${ }^{11}$. Ainda que a figura representativa do "Outro" conduza o EuTranscental à consciência daquilo que lhe é próprio, segundo Husserl não há o estabelecimento de nenhuma relação ou intercâmbio de experiências entre um e outro. Utilizando esses parâmetros para analisar o romance de Rilke, as seguintes considerações devem ser levantadas: Malte não produz uma dissecação do seu Eu. Ao contrário, seu mundo interior encontra-se em tal estado de caos que lhe resultaria impossível poder dissecar e classificar seus Eus. Além disso, o "Outro" (der Andere) ou

\footnotetext{
${ }^{10}$ Os citados vocábulos foram retirados dos dicionários Duden Universalwörterbuch e Wahrig-Deutsches Wörterbuch.

11 "In dieser Art bewährbarer Zugänglichkeit des original Unzugänglichen gründet der Charakter des seienden Fremden." - Premissa "52. Appräsentation als Erfahrungsart mit ihrem eigenen Bewährungsstil" (V. Meditation) consultada no website: http://www.textlog.de/husserl-cartesianische-meditationen.html.
} 
Martins, R. - Malte Laurids Brigge: novas perspectivas

o "Estranho" (das/der Fremde) em relação a Malte é ele próprio e não uma pessoa ou algo externos a si, como aponta a teoria de Husserl. Ainda que o contato e o confronto com o meio externo estranho de Paris, juntamente com tipos específicos de sua população, sejam essenciais e impulsionem o narrador-protagonista a ter consciência da existência de um "Outro" Malte (inacessível originalmente em seu mundo interior) esse "Outro" não deixa de ser ele próprio, que lhe revela uma nova identidade, um Malte em modificação ${ }^{12}$. A partir da "experiência do estranho" (Fremderfahrung) com a cidade grande e sua população, Malte Laurids Brigge tem acesso ao seu "Outro" (der Andere), um novo e, consequentemente, estranho Malte. Para poder descobrir quem finalmente é, o jovem retorna a vivenciar "experiências do estranho", porém consigo mesmo. E para isso, parte em uma viagem introspectiva, retomando reminiscências de sua infância e leituras colecionadas que ilustram essa sua mesma busca desde tempos passados.

Ao retomar fatos ocorridos em sua infância, Malte reproduz para si mesmo as primeiras experiências de descoberta e afirmação de sua identidade. Essas experiências infantis desafiam o sentido de racionalidade do leitor, que se vê diante de fatos fantásticos que emergem à consciência do protagonista como uma reação imediata às experiências particulares e perturbadoras que vive em Paris. Ou seja, através do choque com o meio exterior de Paris, Malte inicia seu "aprendizado de ver", um fenômeno que o atinge em sua consciência e "des-cobre" imagens mnêmicas de determinados acontecimentos de sua infância. Assim, "o tempo atual e passado coincidem: através das experiências presentes em Paris, as imagens da memória se transformam, as quais surgem repentinamente à consciência e são selecionadas através do olhar retrospectivo.”, conforme analisa o crítico Hansgeorg SCHMIDT-BERGMANN (in RILKE 2000: 238) ${ }^{13}$. O modo que Malte encontra para narrar suas experiências modernas adequadamente é a reflexão do que experienciou e a reconstrução do passado, ainda segundo Schmidt-Bergmann (cf. RILKE 2000: 241). Com isso observamos um processo de reflexo que acontece entre as anotações de seu presente e passado: Malte busca nas “experiências do estranho" (Fremderfahrungen) de seu passado um possível consolo

\footnotetext{
${ }^{12}$ Tradução de Lya Luft: "Para que diria a outra pessoa que estou me modificando? Se me modifico, não sou aquele que fui; sou algo diferente do que até agora era, então é evidente que não tenho conhecidos.", in: RILKE 1996: 9.

13،Aktuelle und vergangene Zeit fallen zusammen, unter den gegenwärtigen Erfahrungen in Paris gestalten sich die Bilder der Erinnerung um, die plötzlich in das Bewußtsein treten und durch den retrospektiven Blick selektiert werden.”.
} 
Martins, R. - Malte Laurids Brigge: novas perspectivas

para as "experiências do estranho" de seu presente.

O retorno ao seu passado na Dinamarca parece oferecer a Malte, segundo Franz Loquai, uma salvação diante de seu desesperado e caótico presente. Com a recuperação de sua infância, o protagonista espera superar sua crise atual e seus medos (cf. RILKE 2005: 228). Ou seja, para fugir do desconsolo e do caos de seu presente, Malte parte para as lembranças de seu passado. Contudo, através das anotações dessas recordações infantis, o leitor percebe que essa fase de sua vida tampouco fora idílica, harmônica e segura em seu seio familiar. Ainda segundo LOQUAI. "O pequeno Malte vive a infância não em uma atmosfera de harmonia e segurança (quando muito em companhia da mãe e Abelone), mas em sinais de medos do sótão, aniversários fracassados, segredos, mascaramentos, deformações." (in RILKE 2005: 228) ${ }^{14}$. Ao longo de todos aqueles anos, Malte carregara consigo toda essa bagagem de experiências e emoções de seu passado. Selecionando-as pontualmente em suas anotações, ele produz um valioso material mnêmico com significativos elementos de seu desenvolvimento psíquico. As recordações infantis selecionadas por Malte não seguem uma ordem cronológica - e tampouco podem ser consideradas um material fidedigno de determinados acontecimentos passados. Contudo, quando se trata de expressar fatos passados, principalmente da infância, o que importa não é o fato narrado em si, mas o modo como ele é relembrado (cf. ZAVARONI 2007: 65). Com isso, entende-se que analisar as lembranças infantis de Malte é um importante meio para entendê-lo como adulto.

Segundo a Psicanálise, as experiências vividas nos primeiros anos por uma pessoa geram fatores em sua constituição psíquica e estruturação subjetiva que lhe acompanharão por toda a vida. No ensaio Eine Kindheitserinnerung aus Dichtung und Wahrheit" (1917) Sigmund Freud afirma: "Más bien era lícito suponer que lo conversado en la memoria era también lo más significativo de toda esa época de la vida, ya fuese que poseyera esa importancia en su tiempo o la hubiera adquirido con posterioridad por el influjo de vivencias más tardias.” (FrEUD 1994: 142) ${ }^{15}$. As recordações mantidas da infância apontam para os segredos da alma do adulto e, no caso de Malte, ilustram metaforicamente seus desejos, descobertas e traumas na busca

\footnotetext{
14،"Der kleine Malte erlebt die Kindheit nicht in einer Atmosphäre von Harmonie und Geborgenheit (allenfalls im Umkreis der Mutter und Abelones), sondern im Zeichen von Dachkammerängsten, mißunglückten Geburtstagen, Heimlichkeiten, Maskierungen, Deformationen.)”.

${ }^{15}$ As citações das obras de Freud foram retiradas da tradução ao espanhol por uma opção da autora.
} 
Martins, R. - Malte Laurids Brigge: novas perspectivas

pela determinação de sua identidade desde essa época.

\title{
A mão da parede
}

Seguindo a apresentação desordenada das anotações em seu presente, Malte registra de forma igualmente descontínua e fragmentária algumas recordações de sua infância. Uma delas trata de um insólito acontecimento, uma "experiência do estranho" (Fremderfahrung) que o marcou profundamente e esteve silenciosamente registrada em sua consciência até que, finalmente, emerge à verbalização pela primeira vez nessa anotação:

\begin{abstract}
Assim - coisa bastante estranha - esta é a primeira vez que (e afinal apenas para mim mesmo) conto um fato da minha longínqua infância. Vejo como devia ser pequeno naquele tempo, porque estou ajoelhado em uma poltrona para alcançar comodamente a mesa na qual desenho. Era ao entardecer, no inverno, se não me engano, em nossa casa da cidade. A mesa estava no meu quarto entre as janelas, e não havia lampião no quarto além daquele que iluminava as minhas folhas e o livro de Mademoiselle: pois Mademoiselle estava sentada ao meu lado, um pouco inclinada para trás lendo. $\mathrm{O}$ fato é que naquela noite eu desenhava um cavaleiro, um único, muito nítido, num cavalo de estranhas vestimentas. (RILKE 1996: 62-63)
\end{abstract}

Observa-se que ao cair da noite, o pequeno Malte, na companhia de sua governanta, desenhava um cavaleiro. Essa informação inicial indica sutis detalhes que sugerem importantes considerações para a interpretação do acontecimento que se seguirá. Examinados como encobridores, esses detalhes de relatos da memória do protagonistanarrador ilustram algo aparentemente sem importância. Porém, eles dissimulam marcantes ou traumáticos acontecimentos na primeira infância através de suas ingênuas e encobertas associações. Conforme afirma Sigmund Freud no ensaio "Über Kindheitsund Deckerinnerungen" (1901), essas reproduções mnêmicas encobridoras podem ser consideradas formas substitutas de significativas impressões ou experiências passadas cujo conteúdo, sofrendo algum tipo de resistência inconsciente, encontra-se impedido de ser reproduzido direta e livremente. Mediante esse argumento, os seguintes detalhes podem revelar-nos interessantes cosiderações: 


\section{Martins, R. - Malte Laurids Brigge: novas perspectivas}

1. A figura da mademoiselle ao lado de Malte, acompanhando-o em sua solitária e silenciosa atividade de entretenimento, aponta para a presença marcante das figuras femininas em sua formação. Ela, assim como sua mãe, tem um significativo papel em seu desenvolvimento e concepção de mundo. Observa-se ainda que ao longo de todo o romance o elemento feminino opõe-se drasticamente ao sóbrio e austero mundo masculino que, por meio de personagens como seu pai e seu avô materno, privam e reprimem o garoto de qualquer ação espontânea ou expressão de afetuosidade. Enquanto o universo feminino proporciona a Malte um espaço para o lúdico e a criatividade, para a expansão de suas capacidades, talentos e sentimentos, o universo masculino impõe-lhe distanciamento, frieza e ausência de comunicação nas relações humanas. Finalmente, o gênero feminino é representado não somente como detentor da calidez humana, mas também da intelectualidade. Em seu ato de leitura, mademoiselle tem acesso aos segredos culturais codificados em símbolos gráficos.

2. Outro elemento encobridor na citação anterior encontra-se na figura máscula do cavaleiro. Sua forma tem contorno e definição nítidos - não se trata de um desenho surgido entre rabiscos despretensiosos do garoto. Ao contrário, ele deposita toda a sua concentração e consciência na realização desse desenho. Ora, não se pode ignorar que tal figura posiciona-se contrastivamente frente ao mundo feminino recém-abordado e simboliza uma masculinidade heróica, nobre e virtuosa - também caracterizada como cortesã (höfisch) pelas sociedades medievais e tema de poemas e de canções de amor em língua alemã dessa época (Minnesang). Vale apontar que nessas sociedades, ao mesmo tempo em que o cavaleiro estava submetido a um forte pacto moral pela relação que mantinha com seu senhor e com a irmandade a qual pertencia, aspectos de sua virilidade e, por conseguinte, de sua sexualidade, não podiam ser desconsiderados. Através desse aspecto encobridor do desenho do garoto, o leitor pode supor que Malte estaria prestes a iniciar a descoberta de sua sexualidade (ou do prazer) na primeira infância e, consequentemente, a busca pela de definição de sua identidade.

Na continuação desse fragmento, verifica-se que a cor predominantemente usada por Malte para colorir seu cavaleiro é a vermelha. Sendo o vermelho considerado popularmente a cor do sangue e da paixão, encontra-se nesse detalhe outro aspecto 


\section{Martins, R. - Malte Laurids Brigge: novas perspectivas}

encobridor de sua recordação. A figura do cavaleiro tem sua simbologia viril reforçada pela coloração vermelha do lápis de cor que o menino elege consecutivamente e de forma determinada. Com isso, o leitor tem novamente mais um indício de que tanto a figura do cavaleiro quanto a sua cor encobrem metaforicamente um fato marcante do desenvolvimento psíquico do pequeno Malte. Sobre o efeito psicológico imediato que uma cor produz na alma de um sensível observador, o pintor russo Vassily Kandinsky, (1866-1944) em sua obra "Do espiritual na arte" (1912), disserta: “Aquí aparece la fuerza psicológica del color, que provoca una vibración anímica. La fuerza física elemental es la via por la que el color llega al alma." (KANDINSKY 2010: 52). Mais especificamente sobre o vermelho, o pintor russo afirma que essa cor possui um efeito vital e inquietante em sua própria composição e que ilustra uma nota de grande potência e tenacidade. Seu ardor brioso é um signo da maturidade viril que concentra em si mesmo força e paixão incandescentes, difíceis de serem vencidas (2010: 78-79).

Seguindo o fluxo de sua memória, Malte continua a narração dessa experiência:

Ficou tão colorido que tive de trocar muitas vezes de lápis, mas era especialmente o vermelho que eu pegava. E precisava dele mais uma vez; nisso, o lápis (ainda posso vê-lo) rolou oblíquo sobre a folha iluminada, até a beira da mesa, e, antes que eu pudesse impedi-lo, caiu e sumiu [...] Desajeitado como era, custou-me bastante esforço descer; minhas pernas pareciam longas demais, não conseguia tirá-las de baixo de mim [...] Por fim consegui chegar embaixo, um pouco confuso, encontrando-me sobre uma pele que se estendia desde a mesa até a parede [...] Assim, confiei na minha intuição, e, ajoelhado, e apoiado na mão esquerda, fiquei penteando com a outra o tapete frio, de pêlos compridos, que dava uma sensação aconchegante; só que não se encontrava ali lápis algum.” (RILKE 1996: 63)

Ao cair no chão, o lápis vermelho força a criança a sair de seu plano iluminado em companhia da mademoiselle e de seu ambiente familiar (heimlich) e infantil, para rebaixar-se ao plano sombrio e não familiar (unheimlich) da parte inferior da mesa. A descida da criança ao chão é considerada uma queda simbólica do paraíso perdido de sua inocência infantil. E, assim como a figura bíblica de Adão, Malte, ao ter uma vez contato com o prazer e com o fruto proibido embaixo da mesa, não poderá mais retornar ao seu estado anterior. Após sua expulsão do paraíso, ele estará consciente de que penetrara no mundo dos adultos, local dos segredos do prazer e da sexualidade.

O prazer que Malte sente embaixo da mesa é provocado pelo tato, pelo contato 


\section{Martins, R. - Malte Laurids Brigge: novas perspectivas}

físico com o tapete peludo que, com seus longos fios macios e frios, lhe proporciona uma sensação de conforto e de intimidade. Ao tocar esse tapete, o menino deixa-se guiar por sua intuição e entrega-se ao prazer tátil na penumbra da mesa. No entanto, passados alguns instantes e já acostumado à escuridão, ele começa a distinguir e delimitar o que sua visão reconhece nesse espaço:

Já conseguia distinguir a parede de trás, que terminava com um rodapé claro; orientava-me pelas pernas da mesa; reconhecia sobretudo minha própria mão espalmada, movendo-se solitária lá embaixo, um pouco parecida com algum animal submarino, examinando o fundo. Ainda me lembro de a ter contemplado quase com curiosidade; parecia-me que sabia de coisas que eu não lhe ensinara, pelo modo como se mexia lá embaixo, tateando com movimentos que eu jamais percebera nela. Segui-a, enquanto avançava, aquilo me interessava, estava preparado para qualquer coisa. Mas como poderia estar preparado para o fato de que de repente outra mão viria ao seu encontro, saindo da parede, uma mão maior, de uma magreza incomum, como jamais vira nenhuma. Ela também procurava, vinda do outro lado, e as duas mãos espalmadas aproximavam-se uma da outra cegamente." (RILKE 1996: 63-64)

A partir dos pés da mesa, Malte orienta-se e reconhece a parede com seu rodapé e, sobretudo, sua própria mão, que lhe causa um sentimento de estranhamento devido aos seus movimentos autônomos e desinibidos. A destreza, beleza e leveza desses movimentos sobre o tapete surpreendem-no de tal maneira que ele se encontra fascinado diante de tal espetáculo tátil. Porém, sua espécie de transe é interrompida pela aparição macabra de outra mão que vai ao encontro da sua. Essa "outra mão", saída da parede e com dimensões assustadoras, atrai lentamente a pequena mão do garoto:

Minha curiosidade ainda não estava esgotada, mas de repente acabou-se, ficando apenas o terror. Senti que uma daquelas mãos me pertencia, e estava prestes a se envolver em alguma coisa que nunca mais poderia ser desfeita. Com todo o direito que tinha sobre ela, detive-a, retirei-a devagar, rente ao chão, sem tirar os olhos da outra que continuava procurando. Entendi que ela não desistiria, e não posso dizer como cheguei de novo lá em cima. Fiquei afundado na poltrona, meus dentes batiam, havia tão pouco sangue no meu rosto que pensei também não haver mais azul nos meus olhos. Queria dizer a Mademoiselle, mas não conseguia. No entanto, ela se alarmou, jogou o livro fora, ajoelhou-se ao lado da poltrona, dizendo meu nome; acho que até me sacudiu. Mas eu estava plenamente consciente. Engoli algumas vezes, pois queria contar-lhe tudo. Mas como? Dominei-me de uma maneira indescritível, mas não havia como expressá-lo de modo que alguém o entendesse. (RILKE 1996: 64) 


\title{
Martins, R. - Malte Laurids Brigge: novas perspectivas
}

Observa-se que o surgimento dessa "outra mão" vinda da parede suspende o prazer que Malte estava tendo. Assim como um elemento castrador, essa "outra mão" aparece para reprimir-lhe a descoberta de seu prazer. Aterrorizado com a hipótese de um possível e breve encontro entre esses dois membros, o garoto reúne forças para retirar lentamente sua mão do campo de atração da "outra mão" e, sem saber como, retorna ao plano do tampo da mesa, pálido e mudo. Sua glacial palidez contrasta fortemente com a cor vermelha intensa refletida por seu cavaleiro. Mesmo sentindo a necessidade de relatar a mademoiselle o que acabara de vivenciar embaixo da mesa, ele permanece mudo: as palavras não lhe dão o suporte necessário para sua expressividade; elas são insuficientes para exteriorizar o que realmente sente naquele momento de medo. Else BUDDEBERG afirma que: "Esta experiência foi tão espantosa que seu verdadeiro significado para Malte somente poderia apresentar-se como ele próprio anunciou em seguida: Ele queria contar o que aconteceu, - mas como?" $(1954: 174)^{16}$. Atônito e perdido em si mesmo, ele não logra reproduzir com palavras sua experiência, sua descoberta e seu medo. Verifica-se assim que Malte precocemente vivencia a limitação das palavras, as quais não logram decodificar por meio da linguagem o choque do olhar na cena que presenciou embaixo da mesa. Com isso, essa experiência diante do elemento "estranho" (fremd) da "mão da parede" não o faz descobrir somente seu prazer, como também a crise da linguagem (Sprachkrise) na modernidade. Tal crise denuncia que a linguagem já não é capaz de comportar a necessidade de expressão do homem moderno diante de sua realidade perturbadora e caótica e de sua própria fragmentação (cf. GRIMMINGER 1995: 169-170).

Retomando a experiência da "mão da parede" anos depois, Malte reconhece que já naquele momento tinha claro, ainda que intuitivamente, que havia vivido a perda do paraíso perdido de sua inocência:

\begin{abstract}
Naturalmente é pura imaginação afirmar que naquele tempo já sentira que algo acontecera na minha vida, que algo entrara nela diretamente, algo com que eu teria de andar sozinho, para sempre e sempre. Vejo-me na minha caminha de grades, deitado sem dormir, prevendo indistintamente que a vida seria assim: cheia de coisas singulares, que se destinam a apenas uma pessoa, e que não se podem dizer. O certo é que aos poucos brotou em mim um orgulho triste e pesado. Ficava imaginando como se andaria por aí, cheio de coisas interiores, e
\end{abstract}

\footnotetext{
16 "So schrecknerregend auch dieses Erlebnis an sich gewesen war, seine eigentliche Bedeutung für Malte liegt erst darin, wie er sich weiter dazu verhielt: Er wollte erzählen, - aber wie?"
} 


\section{Martins, R. - Malte Laurids Brigge: novas perspectivas}

em silêncio. Senti uma imensa simpatia pelos adultos. (RILKE 1996: 64-65)

Sua descoberta do prazer, fato considerado por Malte como algo singular e destinado a cada pessoa particularmente, também pode ser averiguada pelos seguintes elementos encobridores revelados depois de tantos anos:

Ao atingir o plano embaixo da mesa e já acostumado à penumbra ali reinante, Malte podia ter, além da visão da parede e de seu rodapé, a visão das pernas de sua governanta. Tal fato não é mencionado explicitamente, porém pode ser intuído a partir do elemento encobridor das "pernas da mesa", as quais lhe serviram como orientação para reconhecer o ambiente e sua própria mão. Popularmente, as pernas são consideradas como um canal do despertar da curiosidade sexual e, consequentemente, um caminho para o alcance do órgão genital feminino. Assim, as "pernas da mesa" podem ser uma referência encobridora às pernas da governanta, que estavam despertando a curiosidade sexual do menino nessa etapa de sua vida. Vale também argumentar que em muitas famílias tradicionais a função de uma governanta consistia tanto no trabalho como tutoras acadêmicas quanto na iniciação sexual dos meninos. Portanto, a "mão da parede" surge como um objeto de castração que tanto interrompe o prazer de seus movimentos manuais quanto lhe impossibilita ver as pernas da governanta e, em consequência disso, tocá-las.

Outro fato que ainda deve ser apontado como revelador da descoberta de sua sexualidade é a reação do menino após essa experiência: ele não ousara narrá-lo a sua mãe $\mathrm{e}^{17}$. E isso não se deve à limitação do poder de expressão das palavras que Malte havia experienciado com mademoiselle, mas à tomada de consciência de que havia descoberto o segredo do mundo dos adultos e, com isso, sepultado a relação de dependência e desejo que tinha com sua genitora. Através dessa "experiência do estranho" (Fremderfahrung), a mãe perdera naturalmente seu posto de objeto de desejo para ele. Tal dissociação emocional e psíquica entre ambos pode ser considerada como o sepultamento do complexo de Édipo e o prenúncio do início de uma próxima etapa da vida de Malte - se nos basearmos no ensaio "El sepultamiento del complejo de Edipo" de Sigmund Freud (1924):

\footnotetext{
17،Um dia, quando quase escurecera completamente durante esse relato, quis contar a mamãe sobre a "mão": nesse momento teria conseguido. (...) E apesar da escuridão tive medo do rosto de mamãe, se visse o que eu vira." (RILKE 1996: 62 - Tradução de Lya Luft).
} 
Martins, R. - Malte Laurids Brigge: novas perspectivas

Otra concepción dirá que el complejo de Edipo tiene que caer porque ha llegado el tempo de su disolución, así como los dientes de leche se caen cuando salen los definitivos. Es verdade que el complejo de Edipo es vivenciado de manera enteramente individual por la mayoría de los humanos, pero es también un fenómeno determinado por la herencia, dispuesto por ella, que tiene que desvanecerse de acuerdo con el programa cuando se inicia la fase evolutiva siguiente, predeterminada. (FREUD 2000: 181-182)

Devido ao medo da reação materna diante de sua revelação, Malte calou-se e guardou para si tal experiência. Quando retoma a experiência da visão da "mão da parede" anos mais tarde, ilustra-a como o início de sua busca pela definição de sua identidade. Para isso, fora preciso estabelecer um corte frente à presença influenciadora e manipuladora da mãe. Sendo muitas vezes privado de sua companhia e, a fim de preencher suas necessidades afetivas, o garoto costumava vestir-se de menina e comportar-se como tal sob a atenção da mãe, que sempre havia desejado ter uma filha. Em uma espécie de encenação grotesca, Malte incorporava o papel de um outro como uma estratégia de aproximação com a mãe, seu objeto de desejo naquela fase da vida

Lembrávamo-nos de que houvera um tempo em que mamãe desejava que eu fosse uma meninazinha, e não esse menino que, enfim, eu era. De alguma forma eu adivinhara aquilo, e tivera a ideia de às vezes bater na porta de mamãe à tarde. Quando ela perguntava quem era, eu me sentia feliz ao dizer: "Sofia", fazendo minha voz miúda tão delicada que me fazia cócegas na garganta. E, quando, entrava (na roupa caseira semelhante à de uma menina que eu sempre usava, com as mangas arregaçadas), era simplesmente Sofia, a pequena Sofia de mamãe, que fazia trabalhos domésticos, e em quem minha mãe tinha de fazer uma trança, para que não pudesse ser confundida com aquele malvado Malte quando ele voltasse. E não desejávamos que voltasse; tanto mamãe quanto Sofia preferiam que ficasse longe, e suas conversas (em que Sofia continuava com aquele tom e voz agudo e sempre igual) constavam geralmente do relato de artes de Malte, e de queixas quanto a ele. "Pois é, esse Malte", suspirava mamãe. Sofia sabia uma porção de coisas sobre a ruindade dos meninos em geral, como se conhecesse muitos deles. (RILKE 1996: 67)

Um dado interessante a ser ressaltado é o fato de que o próprio Rilke havia sido vestido e criado como uma menina até seus cinco anos de idade por sua mãe, Sophie (cf. RILKE 2000: 281; BUDDEBERG 1954: 3).

Com a anotação acima, percebe-se que Malte preferiu não correr o risco de decepcionar sua mãe contando-lhe a experiência da "mão da parede" porque estaria mostrando-lhe definitivamente que não era a pequena e frágil Sofia e que ela deixara de 


\section{Martins, R. - Malte Laurids Brigge: novas perspectivas}

ser seu objeto de desejo. Ao contrário: assumindo a descoberta de seu prazer, o garoto estaria registrando a marca de sua masculinidade, a busca por sua identidade em detrimento da identidade de Sofia e, concomitantemente, sepultando o complexo edipiano que o ligava fortemente a sua genitora. Seu silêncio é um ato consciente e ilustra sua autorrepressão em virtude da obediência e submissão a convenções familiares corporificadas na figura materna. Não é gratuitamente que Malte logra verbalizar pela primeira vez essa experiência através de lembranças encobridoras, quando se encontra em uma terra estrangeira e distante de qualquer relação familiar. Em Paris, ele dispõe de toda a liberdade que necessita para buscar e assumir quem é. Ali, ele pode criar-se, recriar-se e descobrir-se continuamente sem estar atado a nenhuma regra social ou familiar.

Progressivamente às recordações infantis seguem histórias exemplares e leituras de narrativas alheias que lhes serviram de modelos, conforme observa SCHMIDTBERGMANN (cf. RILKE 2000: 241). Wilhelm LOOCK aponta ainda que a apresentação dessas histórias, juntamente com reflexões histórico-filosóficas e sabedorias de vida, ocupa uma posição importante no romance. Elas são abordadas conscientemente por Malte em contraste com as impressões que adquire da realidade de miséria de Paris nos primeiros anos do século XX (1971: 73). A exemplo da história do falso czar Grischa Otrepjow, Malte resgata narrativas exemplares e fatos históricos com o intuito de obter deles aconselhamentos práticos, intervenções utilitárias da experiência de um "narrador maior" capaz de orientá-lo em seu caótico presente na capital francesa. Tal concepção de narrador como um conselheiro prático nos remete ao ensaio de Walter Benjamin "O narrador. Considerações sobre a obra de Nikolai Leskov" (1936). Nesse texto, a figura do narrador é apresentada como emblemática e reconhecida entre mestres e sábios por seu dom de aconselhar seus ouvintes, retirando de suas próprias experiências passadas práticos ensinamentos de vida: “O senso prático é uma das características de muitos narradores natos. [...] o narrador é um homem que sabe dar conselhos." (BENJAMIN 1994: 200). Diante das considerações de Benjamin, observa-se que a arte narrativa de "narradores maiores" abordadas por Malte seria seu refúgio da realidade em que se encontra, uma fonte de sabedoria e conforto, em contraste com seu atordoante presente. Tais histórias exemplares não somente o acompanham como uma fiel conselheira por anos a fio, como também se revelam uma iluminadora orientação em meio às experiências que vive no espaço urbano parisiense. Assim, elas seriam uma válvula de 


\section{Martins, R. - Malte Laurids Brigge: novas perspectivas}

escape ao isolamento familiar e social em que Malte se encontra, o qual, ao reproduzilas, busca perspectivas futuras e aconselhamentos práticos para si.

Além disso, essas narrativas exemplares e fatos históricos são uma metáfora para sua própria situação presente, conforme aponta Franz LOQUAI (cf. RILKE 2005: 224). Seus personagens seriam, consequentemente, selecionados por Malte através da identificação e do compartilhamento de semelhantes projetos de vida que tem com eles. Por não lograr captar nenhum ensinamento prático que a cidade grande poderia proporcionar-lhe, o protagonista do romance parte para os ensinamentos de suas leituras e das figuras de narrativas alheias; obtendo com elas tanto um reflexo de si nesses personagens, como também utilizando-os como uma máscara protetora e escondendo-se atrás deles. Através dessas máscaras metafóricas, Malte projeta a si mesmo como um personagem exemplar para seu leitor, como um porta-estandarte de sua geração, de seus contemporâneos.

\section{falso czar Grischa Otrepjow}

O caso da história de Grischa Otrepjow integra uma das narrativas lidas por Malte em seu passado na Dinamarca, sendo retomado em seu presente em Paris. Essa história serve-lhe de máscara para apresentar e definir sua identidade diante do leitor. Do mesmo modo que Otrepjow apropriou-se da identidade de outra pessoa para poder libertar-se de si mesmo e tornar infinitas suas possibilidades de atuação ao se proteger em uma imagem usurpada, Malte faz uso do mesmo artifício, ao se utilizar da figura histórica do falso czar. Com a apropriação dessa história, Malte ilustra a si mesmo e a sua geração, conforme analisa Wilhelm Loock (1971: 97). Tantos anos depois da leitura da história de Grischa, a cena que permanecera impactante na memória do jovem é a da descrição do cadáver dilacerado do falso czar e o anterior encontro que ele tivera com sua suposta mãe, Marie Nagoi. Esta, reconhecendo-o como um usurpador desde o primeiro contato que tiveram, não o havia desmascarado outrora imediatamente diante de toda a corte:

Sabe Deus que impressão me causaram naquele tempo. Mas agora, depois de tantos anos, recordo a descrição do cadáver do falso czar lançado na multidão, 


\section{Martins, R. - Malte Laurids Brigge: novas perspectivas}

jazendo ali por três dias, todo dilacerado e perfurado, com uma máscara diante da cara. [...] Também gostaria de reler o seu encontro com a mãe. Deve ter sido muito seguro, pois mandou-a vir a Moscou; estou convencido de que acreditava tanto em si mesmo que realmente desejava chamar a mãe. [...] Será que a insegurança dele não começou quando ela o reconheceu? Inclino-me a acreditar que a força do czar estava no fato de não ser filho de ninguém. (RILKE 1996: 122)

O conteúdo desse enredo provém da história russa: trata-se do assassinato em 1591 do herdeiro do czar Ivã IV (Ivã, o Terrível: 1530-1584), Dimitrij Iwanowitch, que na época tinha dez anos de idade, segundo comentário de August STAHL (CF. RILKE 1996: 985986). Esse assassinato permitiu a Boris Godunow ascender ao trono, fator que o tornou o principal suspeito pela misteriosa morte da criança. No entanto, em 1605, Godunow foi destituído do poder por Grischa Otrepjow, que reclamava ser Dimitrij Iwanowitch, o sobrevivente herdeiro de Ivã IV, salvo inexplicavelmente do atentado sofrido em 1591. Otrepjow foi reconhecido como Dimitrij Iwanowitch pela corte russa e familiares. Todavia, Otrepjow não logrou firmar-se por muito tempo como czar: um ano após sua coroação, foi assassinado. Rilke não somente se apropriou desse intrigante fato da história russa mas o reelaborou em seu romance a fim de que seu protagonista pudesse apropriar-se também da identidade de Grischa Otrepjow.

Sendo, em sua essência, estranhos e estrangeiros em relação ao ambiente em que se encontram, Malte e Otrepjow têm um novo e particular estado de felicidade, a qual é sustida por sua situação de "eternidade em fuga" ou de "transitório perpétuo", numa referência à obra de Julia Kristeva Estrangeiros para nós mesmos (1994: 12). A filósofa búlgara disserta sobre a ventura do estrangeiro como a "sensação de uma felicidade especial, um pouco insolente no estrangeiro. A felicidade parece transportá-lo, apesar de tudo, porque alguma coisa foi definitivamente ultrapassada: é uma felicidade do desenraizamento, do nomadismo, o espaço de um infinito prometido." (KRISTEVA 1994: 12). Baseando-se nessa perspectiva de Kristeva, observa-se que tanto no caso de Malte quanto na história de Grischa Otrepjow há uma ausência da manifestação do desejo de retornar a sua pátria ou à casa familiar (no caso do primeiro) ou retomar sua verdadeira identidade (no caso de segundo). Livres de qualquer laço emocional ou familiar, ambos gozam da liberdade e da particular felicidade do desenraizamento; eles têm a possibilidade de construir suas identidades sem intervenções, influências ou pressões de seu passado ou ambiente de origem. No entanto, o preço dessa absoluta liberdade é o 


\section{Martins, R. - Malte Laurids Brigge: novas perspectivas}

estado de solidão e isolamento social em que têm de viver. Desse modo, Malte e Otrepjow encontram-se ilimitados em seus atos e suas escolhas, porém limitados à solidão.

No trecho citado do romance tem-se a voz narrativa em primeira pessoa de Malte afirmando que a força de Otrepjow "estava no fato de não ser filho de ninguém”. A situação de orfandade eleita pelo falso czar conferia a ele força para seguir apoiando sua atuação. Segundo a análise de Julia Kristeva sobre a orfandade do estrangeiro, este vivencia um estado extasiado de independência, conferida pelo prazer de estar isento de qualquer obrigação ou dever:

\footnotetext{
Ser desprovido de pais - ponto de partida da liberdade? Certamente o estrangeiro se embriaga com essa independência e, sem dúvida, o seu próprio exílio inicialmente não passa de um desafio à fertilidade parental. Quem não viveu a audácia quase alucinatória de se pensar sem pais - isento de dívidas e deveres - não compreende a loucura do estrangeiro, o que ela proporciona como prazer ('Sou meu único senhor'), o que ela contém de homicídio raivoso ('Nem pai, nem mãe, nem Deus, nem senhor...'). (KRISTEVA 1994: 28)
}

Consequentemente, a sua única obrigação é ser aquele e fazer somente aquilo de que tem vontade ou aquilo que seu desejo indica. Se, por um lado, o fato de ser um estranho em sua essência permitiu a Grischa Otrepjow consolidar-se no poder, por outro, a ignorância do povo de não saber quem ele realmente era firmava cada vez mais sua liberdade e seu "alles-Sein" (tudo-ser). Assim como o artista tem poder e força sobre sua criação, Otrepjow, ao interpretar o czar Dimitrij Iwanowitch, exerce seu poder de persuasão sobre o povo e seu mundo interior, criado através de uma mentira, suporta todo um novo mundo externo (cf. LOOCK 1971: 98). Nesse novo mundo criado a partir da imagem do czar, Otrepjow encontra uma barreira ameaçadora: Marie Nagoi, a czarina-mãe, que o reconhece como um impostor. Ela, porém, conscientemente aceita sua atuação e participa de sua atuação, reduzindo-o, assim, à condição de um indivíduo que ele não era:

O povo, que o desejara como chefe sem imaginar como ele seria, tornara-o apenas mais livre e ilimitado. Mas a declaração da mãe, mesmo sendo uma mentira consciente, teve o poder de reduzi-lo; retirou-o da plenitude de suas fantasias; limitou-o a uma desgastada imitação; rebaixou-o à condição desse indivíduo que ele não era; tornou-o um embusteiro. (RILKE 1996: 122) 


\section{Martins, R. - Malte Laurids Brigge: novas perspectivas}

Marie Nagoi sustenta a farsa que Grischa criara em torno de si, em um mundo novo cujas bases estão fixadas em instâncias exteriores e alheias a ele: na ignorância do povo e no saber da czarina-mãe, a verdadeira detendora da verdade.

Vítima de uma conspiração e prestes a ter sua verdadeira identidade revelada e sofrer sua morte, Grischa Otrepjow não proferiu uma única palavra em sua defesa. A única voz que preencheu o ambiente foi a da czarina-mãe, que finalmente manifestouse, renegando-o, apontando-o como um impostor e determinando, assim, seu trágico final: "Sabe quem está ali; entende que tudo permanecerá em silêncio, sem transição. E virá a voz que conhece de outrora; a voz fina e falsa que se esforça ao máximo. E então escuta a czarina-mãe, que o renega.” (RILKE 1996: 123). Renegado pela czarina-mãe, Grischa Otrepjow pode assumir diante de todos os seus súditos sua verdadeira identidade. No entanto, ele se nega a tal retrocesso e segue usando a máscara de Dimitrij Iwanowitch. Entre punhaladas e o fulminante tiro de pistola, Otrepjow não tirou sua máscara de falso czar. Isso lhe conferiu ainda uma vez mais poder e força para continuar sua atuação de forma consequente e ser quem desejava. A distância entre seu mundo interior e a realidade do mundo externo contribui para que essa força de apropriação de uma identidade alheia se mantivesse inalterada.

Segundo Julia Kristeva, o intervalo verificado entre o estrangeiro e os outros de seu meio exterior fortalece-o:

\footnotetext{
O estrangeiro fortifica-se com esse intervalo que o separa dos outros e de si mesmo, dando-lhe um sentimento altivo, não por estar em posse da verdade, mas por relativizar a si próprio e aos demais, quando estes encontram-se nas garras da rotina da monovalência. (KRISTEVA 1994: 14)
}

Com base no argumento da filósofa búlgara, percebe-se que Grischa Otrepjow preferiu desde o princípio ter sua morte como um czar; toda sua existência se havia desenvolvido ao redor desse propósito. Com isso, Malte retoma sua ideia de que, sendo a morte outro elemento da vida humana, é preciso experienciá-la de forma individual e própria. Como a morte é trivializada na sociedade moderna, a vida, seu oposto correspondente, também estaria seguindo por esse mesmo caminho de banalização. Assim, com essa história exemplar, Malte busca na figura de Grischa Otrepjow a metáfora necessária para designar o valor implícito de particularidade que cada indivíduo deveria ter tanto em vida quanto na morte. Analogicamente, Malte aprende não apenas a ver e a escrever no 


\section{Martins, R. - Malte Laurids Brigge: novas perspectivas}

presente em Paris, mas também a morrer, segundo Franz LOQUAI (CF. RILKE 2005: 230)

- legado recebido por meio da história de Otrepjow. No final dessa anotação, Malte faz um apelo:

Até aqui a coisa vai por si mesma, mas agora, por favor, um contador de histórias, um contador: pois nessas poucas frases que restam há que ressumar uma violência que supere qualquer contradição. Quer seja dito ou não, é preciso poder jurar que, entre voz e tiro de pistola, infinitamente próximos, houve nele, ainda uma vez, poder e força para tudo ser. Caso contrário não se compreenderá essa brilhante coerência: que tenham perfurado o seu robe, apunhalando-o tantas vezes, como se fossem deparar com o obstáculo da sua dureza pessoal. E que na morte ainda usasse, três dias a fio, a máscara a que quase renunciara. (RILKE 1996: 123)

Ele clama por um narrador, um contador de histórias (Erzähler) que lhe possa revelar minuciosamente a violência da cena da morte de Otrepjow. Esse narrador invocado assemelha-se ao de Walter Benjamim que, com sua arte retórica, proporcionaria à história uma coerência necessária e, didaticamente, retiraria dela um aprendizado para o leitor. Jürgen PETERSEN também pondera que "O que o narrador e a narração permitem em um sentido tradicional é aqui reconhecido: apresenta-se algo como um fato imperturbável através do qual se entende o que se passa. O narrador estabelece a coerência e o sentido permitindo ao leitor compreender o fato narrado através de um determinado e reconhecido processo." (1991: 73) ${ }^{18}$. Petersen ainda observa que, pelo fato de o Eu e o mundo estarem separados um do outro, o "estado de ser" (Dasein) tornou-se tão estranho ao homem que ele não entende mais a vida, cuja realidade não reconhece mais e, por isso, não pode ser apresentada (1991: 73). Por isso, Malte clama por um narrador maior, capaz de orientá-lo, aconselhá-lo para decodificar sua realidade.

Com a história de Grischa Otrepjow, Malte retrata a aproximação e a tênue divisão entre realidade e ficção. Explica-se: a fim de abdicar de sua realidade como "não-czar", Otrepjow criou e alimentou a imagem do falso czar em uma ficção própria. Para tanto, parâmetros morais sobre o certo e o errado, o verdadeiro e o falso perderam sua validade ou efeito. O que verdadeiramente importava a ele era a coerência que sua ficção tinha a capacidade de sustentar por si mesma. Por isso, Otrepjow manteve-se

\footnotetext{
18 "Was der Erzähler, was das Erzählen im tradiotionellen Sinne leistet, ist hier zu erkennen: Es stellt etwas als unerschütterliches Faktum dar, wodurch man versteht, was vor sich geht. Der Erzähler stiftet Zusamenhänge, stiftet Sinn und läßt den Leser durch sein bestimmendes, das Erzählte beglaubigendes Verfahren begreifen, worum es geht."
} 


\title{
Martins, R. - Malte Laurids Brigge: novas perspectivas
}

altivo e convencido de seu personagem até seu último suspiro; com a relativização de valores morais, ele estava sendo justamente aquele que queria ser tanto em vida quanto em morte. Nesse aspecto, ele elevou ao máximo a premissa de Arthur Rimbaud (18541891) "Je est un autre" (Eu é um outro). Por sua vez, Julia Kristeva observa que o fato de utilizar muitas máscaras ou "falsos selfs" permite ao estrangeiro estar concomitantemente entre o verdadeiro e o falso:

\begin{abstract}
Narcisismo inveterado? Psicose branca sob o turbilhão do conflito existenciais? Passando uma fronteira (... ou duas), o estrangeiro transformou as suas inquietações em foco de resistência, em cidadela de vida. Aliás, se tivesse ficado em casa, talvez fosse um marginal, um doente, um fora-da-lei... Sem lar, pelo contrário, propaga o paradoxo do comediante: multiplicando as máscaras e os "falsos selfs", ele jamais é inteiramente verdadeiro nem inteiramente falso.
\end{abstract} (KRISTEVA 1994: 16)

Otrepjow teve a oportunidade de confessar seu crime de apropriação de uma falsa identidade. Mas isso faria com que sua complexa e articulada ficção se arruinasse. Contrário a essa opção, ele cumpriu seu projeto, tornando-se por tal motivo um imortal. Sua imortalidade não provém do fato de haver sido por um período determinado o czar Dimitrij Iwanowitch. Ao contrário, ela se justifica pelo fato de ele haver sido o falso czar Grischa Otrepjow em todas as suas possibilidades e consequências, e de essa imortalidade ter sido alcançada graças a sua coerente amoralidade. Observa-se com isso que, essencialmente, seu projeto não era ser um czar, mas sim um imortal.

Paralelamente, pode-se observar que a invenção do falso czar seria um símile, uma alegoria pela qual o autor mortal Rainer Maria Rilke expressa seu desejo de alcançar semelhante imortalidade por meio do personagem Malte. Seguindo essa lógica, Malte seria, então, uma máscara, um "falso self” de Rilke, no sentido abordado por Julia Kristeva (1994: 16). Não sendo nem inteiramente verdadeiro nem inteiramente falso, Malte ilustra sutilmente o desejo de seu autor em perpetuar-se na história e na literatura universal. Cabe ao leitor, portanto, confirmar se tal feito foi logrado. Todavia uma coisa é certa: assim como o nome de Dimitrij Iwanowitch remete imediatamente a Grischa Otrepjow, Malte Laurids Brigge remete, com igual impressão, efeito e rapidez, a Rainer Maria Rilke. 
Martins, R. - Malte Laurids Brigge: novas perspectivas

\section{Conclusão}

Com o final abrupto do romance através da releitura de Malte sobre a história bíblica do filho pródigo, o leitor não está certo em relação à hipótese de ele ter feito sua peregrinação interior rumo à definição de sua identidade, cumprindo-a com êxito ou não. De forma inacabada e aberta a narrativa se encerra aos olhos ao leitor, que não recebe nenhuma informação adicional sobre o presente e tampouco sobre o futuro do jovem dinamarquês.

Sua viagem subjetiva, iniciada como uma forma de reação imediata ao seu contato conflituoso com a realidade externa da cidade grande, resgata "experiências do estranho" (Fremderfahrungen) de sua infância e de leituras de sua formação. Através de suas experiências infantis, Malte assume que, desde sua primeira infância, buscava a definição de sua identidade, ainda que timidamente, pois se via atado às convenções socias e expectativas de sua tradicional família. Como uma fuga de escape, suas leituras formaram-no e consolaram-no por anos a fio nessa tarefa de se definir. Usando personagens históricos ou exemplares como um espelho, Malte se permite ser ou expressar seus desejos, anseios e pensamento através deles. Tanto suas recordações infantis quanto suas leituras absorvem-no do choque com sua realidade em Paris, mas o confrontam com seus abismos interiores e medos reprimidos.

Projetando seu caótico e fragmentário estado anímico nas anotações sobre a capital francesa, Malte retrata-a como um território não familiar, estranho e estrangeiro. Porém, concomitantemente, como um espaço propício para sua busca, afinal encontrase longe de qualquer pressão familiar ou convenção social. Ele está certo de que ali não voltará mais a se encontrar com a repressora "mão da parede" que lhe reprimirá seus desejos. Estando em um lugar ao qual não pertence, o jovem pode narrar em alto e bom som todas as descobertas e experiências que tem sem necessitar calar-se diante da desaprovação de alguém ou de alguma regra social. Não ser filho de ninguém conferelhe também uma força que, até então, desconhecia. No caótico espaço de Paris, Malte também goza da liberdade necessária para incorporar em si os personagens que quiser. Assim como Grischa Otrepjow, o jovem dinamarquês tem, na cidade estrangeira, a possibilidade de usar as máscaras necessárias para encenar coerentemente sua própria ficção; ali, ele se encontra ilimitado em todas as suas opções e formas de procurar 
Martins, R. - Malte Laurids Brigge: novas perspectivas

definir sua identidade. A sua grande tarefa em Paris é buscar a si mesmo através de todas as formas que ela permite e oferece.

Passados mais de cem anos desde sua primeira publicação, Die Aufzeichnungen des Malte Laurids Brigge segue desafiando o leitor que percorre suas folhas em busca de um elo semântico entre seus setenta e um fragmentos. Devido a sua proposta narrativa, linguagem e forma, o romance não é um texto fácil. Contudo, sua multiplicidade de temas, gêneros e diálogos com diversas áreas do conhecimento humanístico tornam-no um valioso testemunho do pensamento do homem moderno. Nesse ponto, o leitor contemporâneo pode ler Die Aufzeichnungen des Malte Laurids Brigge como uma provocação enigmática de Rilke: Não seríamos todos estranhos ou estrangeiros para nós mesmos? Não deveríamos ser como o "falso czar" procurando viver nossas ilimitações e de forma coerente todas as nossas facetas? Não necessitaríamos da máscara de um "outro" (der Andere) para termos acesso ao nosso “inacessível original”? Através dessa orientação modelar, o romance de Rainer Maria Rilke confronta o leitor atual com suas próprias convenções, fragmentos interiores, estados de tensão e desorientação. Contudo, o texto oferece-lhe o espaço livre necessário para comportar outras formas de interpretação possíveis. A abertura de significados torna Die Aufzeichnungen des Malte Laurids Brigge uma leitura exemplar.

\section{Referências biliográficas}

BENJAMIN, Walter. "O Narrador. Considerações sobre a obra de Nikolai Leskov". In: Magia e técnica, arte e politica. Obras escolhidas - Vol.I. Tradução: Sérgio Paulo Rouanet. São Paulo: Ed. Brasiliense, 1994.

BUDDEBERG, Else. Rainer Maria Rilke - Eine innere Bibliographie. Stuttgart: J.B. Metzlersche Verlagsbuchhandlung, 1954.

EAGLETON, Terry. Einführung in die Literatur. Stuttgart: Metzler Verlag, 1997.

EILERT, Heide. "Aspekte der Moderne in Rainer Maria Rilkes Roman Die Aufzeichnungen des Malte Laurids Brigge". In: MALER, Anselm. Europäische Romane der klassischen Moderne. Frankfurt a.M.: Peter Lang Verlag, 2000

FREUD, S. Obras completas - De la historia de una neurosis infantil / El Hombre de los lobos y otras historias 1917-1919. Vol. XVI. Tradução José L. Etcheverry. Buenos Aires-Madrid: Amorrortu Editores, 1994.

FREUD, S . Obras completas - El yo y el ello, y otras obras (1923-1925). Vol. XIX. Tradução José L. Etcheverry. Buenos Aires-Madrid: Amorrortu Editores, 2000.

FREUD, S. Obras completas - Psicopatologia de la vida cotidiana (1901) Vol. VI. Tradução José L. Etcheverry. Buenos Aires-Madrid: Amorrortu Editores, 2004. 
Martins, R. - Malte Laurids Brigge: novas perspectivas

FREUD, S. Introducción al psicanálisis. Tradução: Luiz López B. Torres. Madrid: Alianza Editorial, 2005.

FREUD, S. Obras completas - La interpretación de los sueños (1900) Vol. IV. Tradução José Etcheverry. Buenos Aires-Madrid: Amorrortu Editores, 2007.

GRIMMINGER, Rolf. Literarische Moderne - Europäische Literatur im 19. und 20. Jahrhundert. Hamburg: Rowohlt Taschenbuch Verlag, 1995.

HAMBURGER, Käte. Rilke: Eine Einführung. Stuttgart: Ernst Klett Verlag, 1976.

Hermann, H. Ridley, H. Rilke und der Wandel in der Sensibilität. Essen: Verlag Die blaue Eule, 1990.

Holthusen, Hans Egon. Rainer Maria Rilke. Hamburg: Rowohlt Taschenbuch, 1990.

Husserl, Edmund. Meditações Cartesianas. Introdução à Fenomenologia. Tradução Maria Gorete Lopes e Sousa. Porto: RÉS Editora, 2001.

KANDINSKY ,Vasili. De lo espiritual en el arte. Buenos Aires: Paidós, 2010.

KRISTEVA, Julia. Estranhos para nós mesmos. Tradução: Maria Carlota Gomes. Rio de Janeiro: Rocco Editora, 1994.

LEISS, I. STADLER, H. Deutsche Literaturgeschichte Band 8 - Wege in die Moderne 1890-1918. München: dtv, 2004.

LoOcK, Wilhelm. Die Aufzeichnungen des Malte Laurids Brigge - Interpretationen.München: R. Oldenbourg Verlag, 1971.

LUKÁCS, Georg. A teoria do romance - Um ensaio histórico-filosófico sobre as formas da grande épica. Tradução: José Marcos. M. Macedo. São Paulo: Editora 34, 2009.

PETERSEN, Jürgen H. "Der Leser als Souverän: Rainer Maria Rilkes 'Die Aufzeichnungen des Malte Laurids Brigge' und Carl Einsteins 'Bebuquin oder die Dilettanten des Wunders'” In: Der Deutsche Roman der Moderne. Grundlegung - Typologi - Entwicklung. Stuttgart: Metzler Verlag, 1991, p. 68-98.

Postman, Neil. O desaparecimento da infância. Trad: José Laurenio de Melo. Rio de Janeiro. Graphia Editorial, 1999.

RiLKe, Rainer Maria. Prosa und Dramen. Org. August Stahl. Frankfurt am Main: InselVerlag, 1996.

RILKE, Rainer Maria . Die Aufzeichnungen des Malte Laurids Brigge. Comentários de Hansgeorg Schmidt-Bergmann. Frankfurt am Main: Suhrkamp Verlag - Basisbibliothek, 2000.

RILKE, Rainer Maria. Die Aufzeichnungen des Malte Laurids Brigge. Comentários de Franz Loquai. München: Wilhelm Goldmann Verlag, 2005.

RILKE, Rainer Maria . Os cadernos de Malte Laurids Brigge. Tradução de Lya Luft. São Paulo: Editora Mandarim, 1996.

VIETTA, Silvio. Die literarische Moderne - Eine problemgeschichtliche Darstellung der deutschsprachige Literatur von Hölderlin bis Thomas Bernhard. Stuttgart: J.B: Metzlersche Verlagsbuchhandlung, 1992.

WALDENFELS, Bernhard. Topographie des Fremden. Frankfurt a.M.: Suhrkamp Verlag, 1997.

ZAVARONI, Dione et al. “A construção do infantil na obra de Freud”. In: Estudos de Psicologia (Natal). V. 12. N.1 Jan-Abril, 2007, p. 65-70. 